TESIS

\title{
ANALISIS SUBSIDI ANGKUTAN PERDESAAN MELALUI BIAYA OPERASI KENDARAAN (BOK) \\ DI KABUPATEN SLEMAN
}

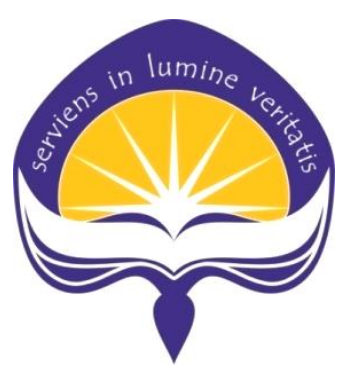

MARJANTO

No.Mhs.: 145102301/PS/MTS

PROGRAM STUDI MAGISTER TEKNIK SIPIL PROGRAM PASCASARJANA UNIVERSITAS ATMA JAYA YOGYAKARTA 2016 


\section{PENGESAHAN TESIS}

Nama

Nomor Mahasiswa

Konsentrasi

Judul Tesis

\author{
MARJANTO \\ 145102301/PS/MTS \\ - Transportasi \\ : Analisis Subsidi Angkutan Perdesaan \\ Melalui Biaya Operasi Kendaraan (BOK) \\ Di Kabupaten Sleman
}

Nama Pembimbing

Dr. Ir. Imam Basuki, M.T.

Ir. Yohanes Lulie, M.T.

\section{Tanggal}

$29.01-2016$

$20 \cdot 0 \% \cdot 20 / 6$
Tanda Tangan

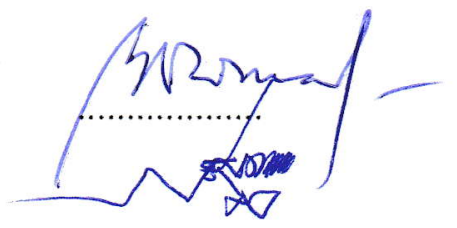




\section{PENGESAHAN TESIS}

\section{Nama \\ Nomor Mahasiswa \\ Konsentrasi \\ Judul Tesis}

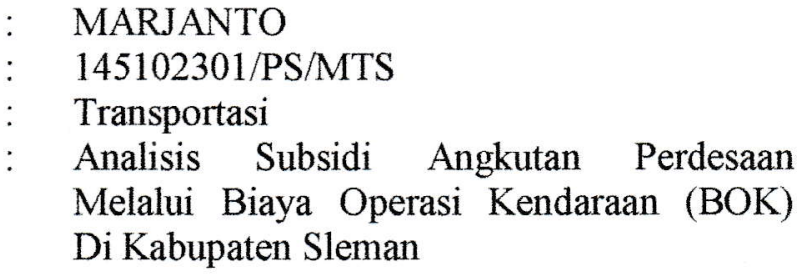

\section{Nama Penguji}

Dr. Ir. Imam Basuki, M.T

Ir. Yohanes Lulie, M.T.

Ir. Hendra Suryadharma, M.T.
Tanggal

29.01 .2016

$29.01 \cdot 20 / 6$

...................

Tanda Tangan

29. 0.2 .2016

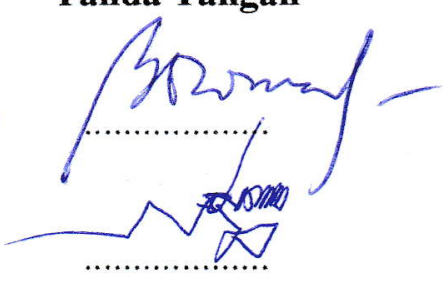

A Ketua Program Studi

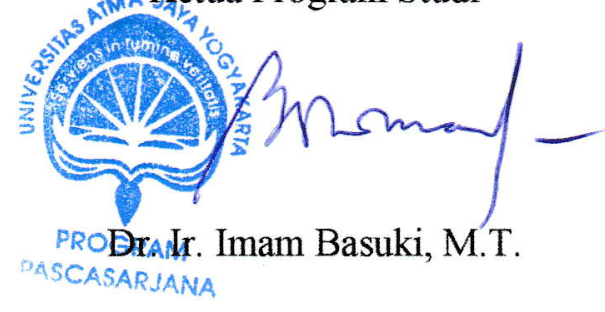




\section{PERNYATAAN}

Saya yang bertanda tangan di bawah ini menyatakan dengan sesungguhnya bahwa Tugas Akhir dengan judul:

\section{ANALISIS SUBSIDI ANGKUTAN PERDESAAN MELALUI BIAYA OPERASI KENDARAAN ( BOK ) DI KABUPATEN SLEMAN}

benar-benar merupakan hasil karya saya sendiri dan bukan merupakan hasil plagiasi karya orang lain. Ide, data hasil penelitian maupun kutipan langsung maupun tidak langsung yang bersumber dari tulisan atau ide orang lain dinyatakan secara tertulis dalam tugas akhir ini. Apabila terbukti dikemudian hari bahwa Tugas Akhir ini merupakan hasil plagiasi, maka ijasah yang saya peroleh dinyatakan batal dan akan saya kembalikan kepada Rektor Universitas Atma Jaya Yogyakarta.

Yogyakarta, Januari 2016

Yang membuat pernyataan

( Marjanto ) 


\section{KATA PENGANTAR}

Puji syukur kehadirat Allah SWT atas limpahan berkat, rahmat dan karunia-nya sehingga penulis dapat menyelesaikan Tugas Akhir dengan judul “Analisis Subsidi Angkutan Perdesaan Melalui Biaya Operasi Kendaraan (BOK) Di Kabupaten Sleman”, sebagai syarat menyelesaikan pendidikan pada Magister Teknik Sipil Program Pascasarjana Universitas Atma Jaya Yogakarta.

Dalam menyusun Tugas Akhir ini penulis telah banyak mendapat bimbingan, petunjuk dan petunjuk dari berbagai pihak. Oleh karena itu pada kesempatan ini penulis ingin menyampaikan ucapan terima kasih kepada pihakpihak yang telah membantu dalam penyelesaian Tugas Akhir ini kepada :

1. Bapak Drs. M. Parnawa Putranta, MBA., Ph.D., selaku Direktur Pascasarjana Universitas Atma Jaya Yogyakarta.

2. Bapak Dr. Ir. Imam Basuki, M.T., selaku Ketua Program Studi Magister Teknik Sipil Universitas Atma Jaya Yogyakarta.

3. Bapak Dr. Ir. Imam Basuki, M.T., dan Bapak Ir. Yohanes Lulie, MT., selaku Dosen Pembimbing yang telah bersedia meluangkan waktunya dengan sabar dan teliti dalam membimbing sehingga Tugas Akhir ini dapat diselesaikan pada waktunya.

4. Seluruh Dosen, karyawan, dan staf Magister Teknik Sipil Universitas Atma Jaya Yogyakarta yang telah bersedia mendidik, mengajar dan memberikan ilmunya kepada penulis. 
5. Pimpinan dan Staf Dinas Perhubungan Komunikasi dan Informatika Kabupaten Sleman yang telah memberikan dukungan dan dorongan dalam penyelesaian tugas akhir ini.

6. Pimpinan Satuan Kerja Perangkat Daerah (SKPD) Pemerintah Kabupaten Sleman telah banyak membantu dalam pengumpulan data dalam penyelesaian Tugas Akhir ini.

7. Keluarga tercinta, istriku Suryarini Sri Handayani,S.E, kedua buah hatiku Mahatma Adhyaksa Wiryawan (Aksa) dan Athifah Syafa Saskila (Syafa) serta secara khusus kepada kakak kami tercinta Ir. Wisnu Arya Wardhana yang selalu memberikan dukungan, semangat dan doa yang diberikan dengan tulus dan ikhlas.

8. Untuk semua teman-teman seperjuangan Magister Teknik Sipil Angkatan September 2014 dan Angkatan Januari 2015 yang selalu membantu dan memberikan semangat yang luar biasa.

9. Semua pihak yang tidak dapat disebutkan satu - persatu oleh penulis dalam menyelesaikan studi di Magister Teknik Sipil Universitas Atma Jaya Yogyakarta.

Yogyakarta, Januari 2016

Penulis

\section{Marjanto}




\section{DAFTAR ISI}

HALAMAN JUDUL............................................................................... i

HALAMAN PENGESAHAN PEMBIMBING........................................... ii

HALAMAN PENGESAHAN PENGUJI............................................................ iii

LEMBAR PERNYATAAN...................................................................... iv

KATA PENGANTAR............................................... v

DAFTAR ISI................................................................................................. vii

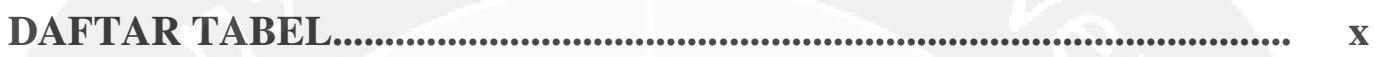

DAFTAR GAMBAR........................................................................................ xii

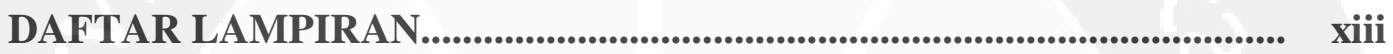

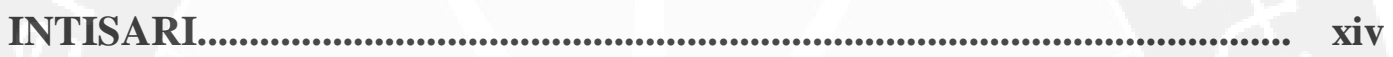

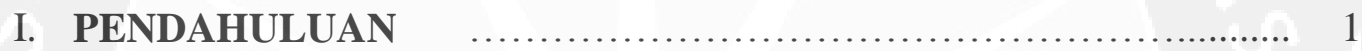

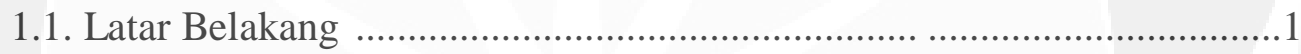

1.2. Perumusan Masalah ............................................................................ 4

1.3. Batasan Masalah .................................................................................. 5

1.4. Keaslian Penelitian ............................................................................. 5

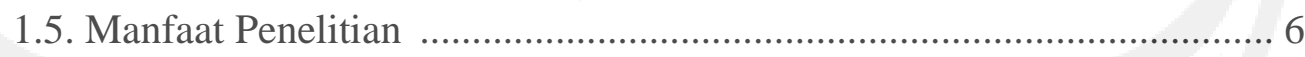

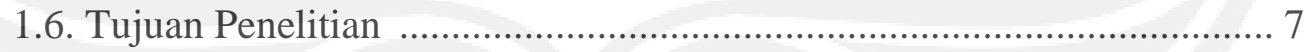

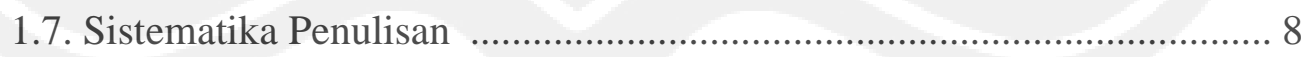

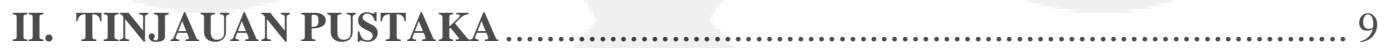

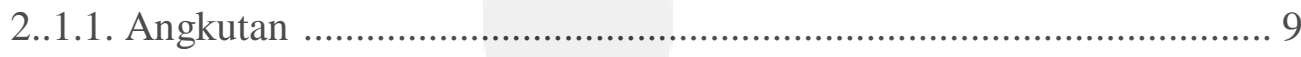

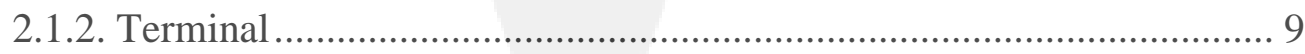

2.1.3. Kendaraan Bermotor Umum atau Angkutan Umum ........................ 11

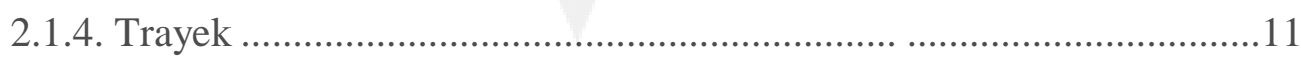

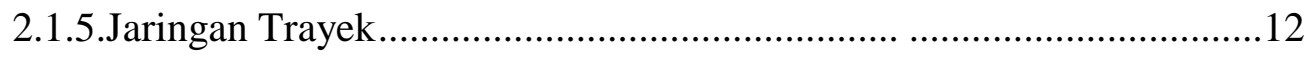

2.1.6. Angkutan Perdesaan .....................................................................16

2.1.7. Ciri-Ciri Angkutan Perdesaan .......................................................17 
2.1.8. Standar Pelayanan Minimal Angkutan Pedesaan . .............................17

2.1.9. Indikator Pelayanan Angkutan Umum...........................................26

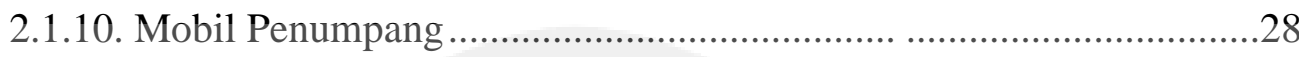

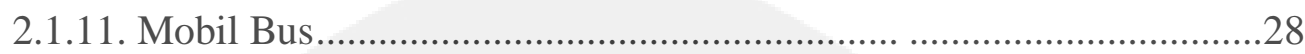

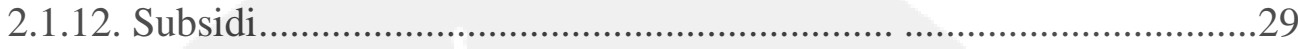

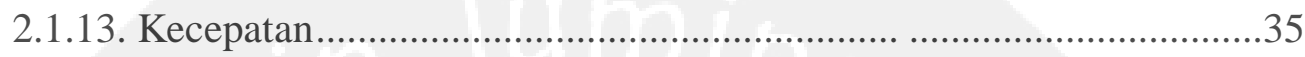

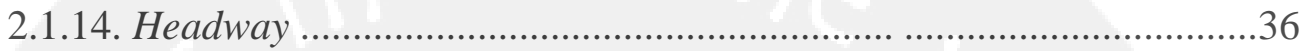

2.1.15. Faktor Muat (Load Factor) ….........................................................36

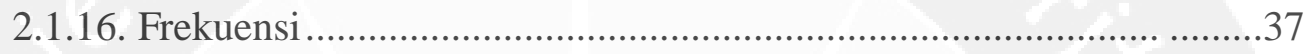

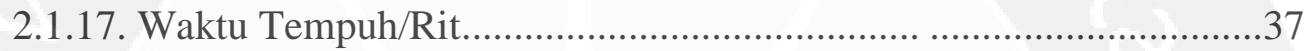

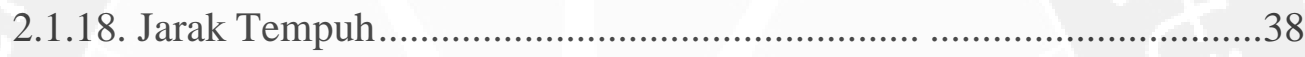

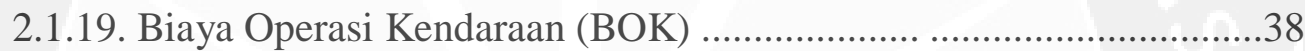

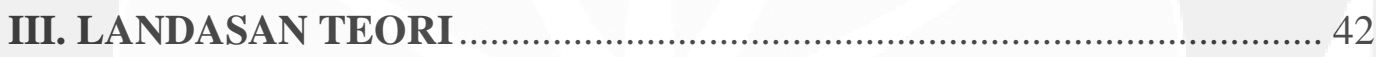

3.1. Kapasitas Kendaraan ........................................................................ 42

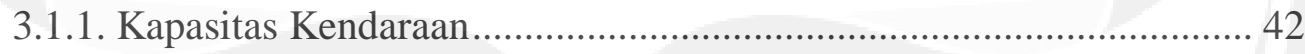

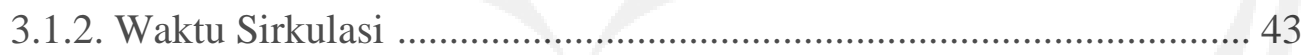

3.1.3. Waktu Henti Kendaraan .................................................................. 44

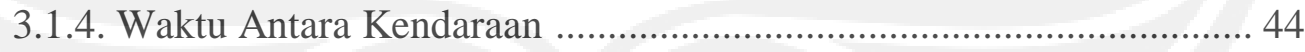

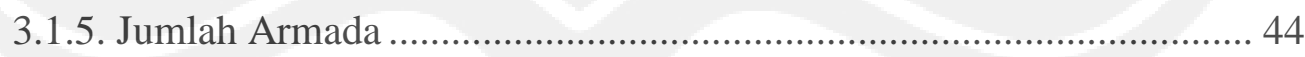

3.1.6. Biaya Operasi Kendaraan (BOK) .................................................... 45

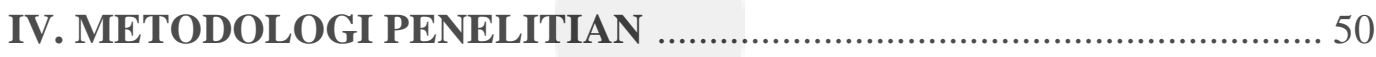

4.1. Bagan Alir Penelitian ........................................................................ 50

4.2. Metode Penelitian ............................................................................... 51

4.3. Metode Pengolahan Data .................................................................. 54

V. HASIL PENELITIAN DAN PEMBAHASAN ...................................... 55

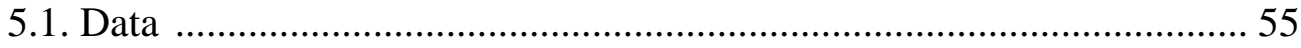

5.1.1 Hasil Survei Instansional .............................................................. 55

viii 
5.1.2. Hasil Survei On Boarding bus atau Survei di Atas Angkutan Umum 55

5.1.3. Hasil Survei Wawancara Operator Angkutan Umum Perdesaan ....... 55

5.2. Hasil Survei Kinerja Angkutan Perdesaan............................................ .56

5.2.1. Data Trayek Angkutan Perdesaan ................................................... 56

5.2.2. Data On Boarding Angkutan Perdesaan ......................................... 64

5.2.3. Hasil Survei Wawancara Operator Angkutan Perdesaan.....................85

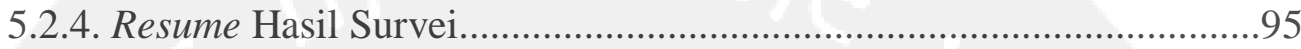

5.3. Hasil Survei Finansial Kendaraan dan Rencana Kinerja Operasional...102

5.3.1 Hasil Survei Biaya Operasional Kendaraan ( BOK)..........................102

5.3.2. Usulan Pengembangan Angkutan Perdesaan.......................................104

5.3.3. Rencana Kinerja Trayek Angkutan Perdesaan .................................106

5.3.4 Analisis Biaya Operasi Kendaraan....................................................110

5.3.5. Skema Pembiayaan Angkutan Perdesaan...........................................121

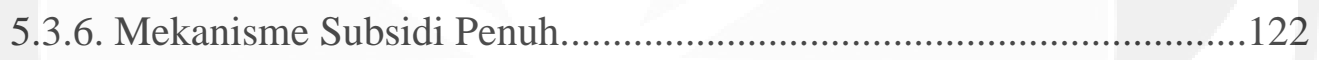

5.3.7. Mekanisme Subsidi Selisih Operasional..........................................124

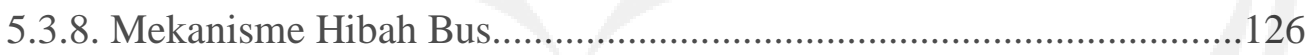

5.3.9. Mekanisme Subsidi BBM..............................................................129

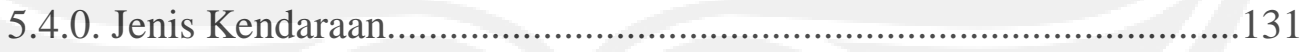

5.4.1. Skema Subsidi Pembiayaan Angkutan Perdesaan.............................132

5.4.2. Resume Perhitungan Pembiayaab Subsidi..........................................133

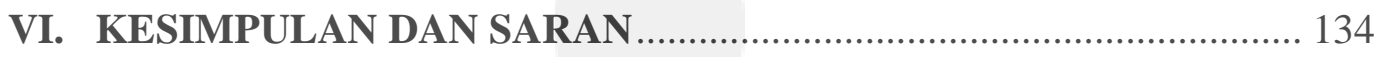

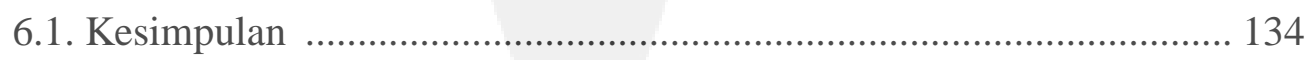

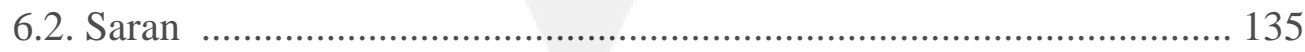

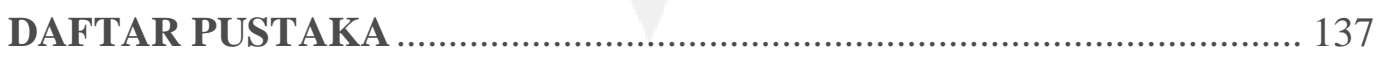

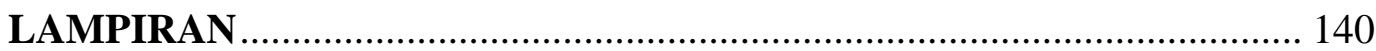


DAFTAR TABEL

\begin{tabular}{|c|c|c|}
\hline NO & KETERANGAN & HAL. \\
\hline 2.1. & $\begin{array}{l}\text { Tabel Standar Pelayanan Minmal Angkutan Orang Dengan } \\
\text { Kendaraan Bermotor Umum Dalam Trayek }\end{array}$ & 18 \\
\hline 2.2 . & $\begin{array}{l}\text { Standar Pelayanan Minmal Angkutan Orang Dengan Kendaraan } \\
\text { Bermotor Umum Dalam Trayek. }\end{array}$ & 22 \\
\hline 2.3 . & Indikator Pelayanan Di Berbagai Kota & 27 \\
\hline 5.1. & Data Trayek Angkutan Perdesaan & 56 \\
\hline 5.2. & $\begin{array}{l}\text { Rangkuman Hasil Survei On Boarding Trayek A3 (Prambanan- } \\
\text { Pulowatu) Pada Waktu Pagi Hari }\end{array}$ & 65 \\
\hline 5.3. & $\begin{array}{l}\text { Rangkuman Hasil Survei On Boarding Trayek D6 (Jombor- } \\
\text { Prambanan) Pada Waktu Pagi Hari }\end{array}$ & 66 \\
\hline 5.4. & $\begin{array}{l}\text { Rangkuman Hasil Survei On Boarding Trayek D6 (Jombor- } \\
\text { Prambanan) Pada Waktu Siang Hari }\end{array}$ & 68 \\
\hline 5.5 . & $\begin{array}{l}\text { Rangkuman Hasil Survei On Boarding Trayek } 26 \text { (Jombor- } \\
\text { Condongcatur) Pada Waktu Pagi Hari }\end{array}$ & 70 \\
\hline 5.6 & $\begin{array}{l}\text { Rangkuman Hasil Survei On Boarding Trayek } 26 \text { (Jombor- } \\
\text { Condongcatur) Pada Waktu Siang Hari }\end{array}$ & 71 \\
\hline 5.7 & $\begin{array}{l}\text { Rangkuman Hasil Survei On Boarding Trayek } 30 \text { (Pasar-Tempel- } \\
\text { Pasar Slerman) Pada Waktu Pagi Hari }\end{array}$ & 73 \\
\hline 5.8 & $\begin{array}{l}\text { Rangkuman Hasil Survei On Boarding Trayek } 30 \text { (Pasar-Tempel- } \\
\text { Pasar Slerman) Pada Waktu Siang Hari }\end{array}$ & 74 \\
\hline 5.9 & $\begin{array}{l}\text { Rangkuman Hasil Survei On Boarding Trayek } 19 \text { (Pasar } \\
\text { Piyungan-Besi) Pada Waktu Pagi Hari }\end{array}$ & 76 \\
\hline 5.10 & $\begin{array}{l}\text { Rangkuman Hasil Survei On Boarding Trayek } 19 \text { (Pasar } \\
\text { Piyungan-Besi) Pada Waktu Siang Hari }\end{array}$ & 77 \\
\hline 5.11 & $\begin{array}{l}\text { Rangkuman Hasil Survei On Boarding Trayek } 16 \text { (Ngapak- } \\
\text { Jombor) Pada Waktu Pagi Hari }\end{array}$ & 79 \\
\hline 5.12 & $\begin{array}{l}\text { Rangkuman Hasil Survei On Boarding Trayek } 16 \text { (Ngapak- } \\
\text { Jombor) Pada Waktu Siang Hari }\end{array}$ & 80 \\
\hline 5.13 & $\begin{array}{l}\text { Rangkuman Hasil Survei On Boarding Trayek } 23 \text { (Terminal } \\
\text { Pakem-Terminal Jombor) Pada Waktu Pagi Hari }\end{array}$ & 81 \\
\hline 5.14 & $\begin{array}{l}\text { Rangkuman Hasil Survei On Boarding Trayek } 23 \text { (Terminal } \\
\text { Pakem-Terminal Jombor) Pada Waktu Siang Hari }\end{array}$ & 82 \\
\hline 5.15 & $\begin{array}{l}\text { Rangkuman Hasil Survei On Boarding Trayek D2 (Pasar Tempel- } \\
\text { TerminaL Condongcatur) Pada Waktu Pagi Hari }\end{array}$ & 83 \\
\hline 5.16 & Hasil Survei On Boarding Angkutan Perdesaan & 84 \\
\hline 5.17 & Kinerja Operasional Angkutan Perdesaan Sleman & 98 \\
\hline 5.18 & Komponen Biaya Operasi Kendaraan & 102 \\
\hline 5.19 & Usulan Trayek Angkutan Perdesaan Sebagai Feeder & 105 \\
\hline 5.20 & Waktu Perjalanan dan Jumlah Putaran & 108 \\
\hline 5.21 & Headway dan Kebutuhan Armada & 109 \\
\hline 5.22 & Rencana Trayek Angkutan Perdesaan & 111 \\
\hline
\end{tabular}




\begin{tabular}{|c|l|c|}
\hline NO & \multicolumn{1}{|c|}{ KETERANGAN } & HAL. \\
\hline 5.23 & Analisis Biaya Operasi Kendaraan & 112 \\
\hline 5.24 & Analisis BOK Dengan Subsidi Penuh & 123 \\
\hline 5.25 & Analisis BOK dengan Subsidi Selisih Biaya Operasional & 125 \\
\hline 5.26 & Biaya Operasi Kendaraan Dengan Subsidi Hibah Bus & 127 \\
\hline 5.27 & Analisis Subsidi BBM & 130 \\
\hline 5.28 & Resume Perhitungan BOK Subsidi & 133 \\
\hline
\end{tabular}


DAFTAR GAMBAR

\begin{tabular}{|c|l|c|}
\hline NO & \multicolumn{1}{|c|}{ KETERANGAN } & HAL. \\
\hline 2.1 & Pola Jaringan Radial & 13 \\
\hline 2.2 & Pola Jaringan Kisi-kisi (grid) & 14 \\
\hline 2.3 & Pola Jaringan Campuran (Mixed) & 15 \\
\hline 2.4 & Pola Jaringan Teritorial & 16 \\
\hline 4.1 & Diagram Alir Penelitian & 50 \\
\hline 5.1 & Kondisi Trayek Angkutan Perdesaan Kabupaten Sleman & 63 \\
\hline 5.2 & $\begin{array}{l}\text { Load Factor Trayek A3 (Prambanan-Pulowatu) Pada Waktu Pagi } \\
\text { Hari }\end{array}$ & 64 \\
\hline 5.3 & $\begin{array}{l}\text { Load Factor Trayek D6 (Jombor-Prambanan) Pada Waktu Pagi } \\
\text { Hari }\end{array}$ & 66 \\
\hline 5.4 & $\begin{array}{l}\text { Load Factor Trayek D6 (Jombor-Prambanan) Pada Waktu Siang } \\
\text { Hari }\end{array}$ & 67 \\
\hline 5.5. & $\begin{array}{l}\text { Load Factor Trayek 26 (Jombor-Condongcatur) Pada Waktu Pagi } \\
\text { Hari }\end{array}$ & 69 \\
\hline 5.6 & $\begin{array}{l}\text { Load Factor Trayek 26 (Jombor-Condongcatur) Pada Waktu Siang } \\
\text { Hari }\end{array}$ & 71 \\
\hline 5.7 & $\begin{array}{l}\text { Load Factor Trayek 30 (Pasar Tempel- Pasar Sleman) Pada Waktu } \\
\text { Pagi Hari }\end{array}$ & 72 \\
\hline 5.8. & $\begin{array}{l}\text { Load Factor Trayek 30 (Pasar Tempel-Pasar Sleman) Pada Waktu } \\
\text { Siang }\end{array}$ & 74 \\
\hline 5.9 & $\begin{array}{l}\text { Load Factor Trayek 19 (Pasar Piyungan-Besi) Pada Waktu Pagi } \\
\text { Hari }\end{array}$ & 75 \\
\hline 5.10. & $\begin{array}{l}\text { Load Factor Trayek 19 (Pasar Piyungan-Besi) Pada Waktu Siang } \\
\text { Hari }\end{array}$ & 77 \\
\hline 5.11. & Load Factor Trayek 16 (Ngapak-Jombor) Pada Waktu Pagi Hari \\
\hline 5.12. & Load Factor Trayek 16 (Ngapak-Jombor) Pada Waktu Siang Hari. \\
\hline 5.13. & $\begin{array}{l}\text { Load Factor Trayek 23 (Terminal Pakem-Terminal Jombor) Pada } \\
\text { Waktu Pagi Hari }\end{array}$ & 79 \\
\hline 5.14. & $\begin{array}{l}\text { Load Factor Trayek 23 (Terminal Pakem-Terminal Jombor) Pada } \\
\text { Waktu Siang Hari }\end{array}$ \\
\hline 5.15. & $\begin{array}{l}\text { Load Factor Trayek D2 (Pasar Tempel-Terminal Condongcatur) } \\
\text { Pada Waktu Pagi Hari }\end{array}$ & 82 \\
\hline 5.16. & Bagan Alir Dana Subsidi Penuh \\
\hline 5.18. & Bagan Alir Dana Subsidi Selisih Biaya Operasi \\
\hline 5.19. & Bagan alir Dana Subsidi BBM & 131 \\
\hline
\end{tabular}




\section{DAFTAR LAMPIRAN}

\begin{tabular}{|c|l|c|}
\hline NO & \multicolumn{1}{|c|}{ KETERANGAN } & HAL. \\
\hline 1. & Perhitungan Biaya Operasional Kendaraan (BOK) Subsidi Bus & 141 \\
\hline 2. & Perhitungan Biaya Operasional Kendaraan (BOK) Subsidi BBM & 152 \\
\hline 3. & Rencana Kinerja Operasional Bus Seat 16 dan 22 & 163 \\
\hline 4. & Peta Angkutan Pendesaan & 164 \\
\hline 5. & Peta Trayek Angkutan Pedesaan Sebagai Feeder & 172 \\
\hline 6. & Survei Onboarding Bus & 192 \\
\hline 7. & Surat Izin Penelitian & 194 \\
\hline 8. & $\begin{array}{l}\text { Foto Survei Wawancara Kepada Pengemudi dan } \\
\text { Survei On Boarding }\end{array}$ & \\
\hline
\end{tabular}




\section{INTISARI}

Pelayanan angkutan perdesaan di Kabupaten Sleman menunjukkan kinerja operasional yang kurang baik dari pelayanan sembilan trayek yang ada, tujuh trayek tidak menjalani lintasan trayek sesuai izin yang ditetapkan, satu trayek sudah tidak beroperasi lagi dan hanya ada satu trayek yang masih menjalankan lintasan trayek sesuai izin trayek.

Tujuan penelitian ini adalah menganalisis kinerja pelayanan sembilan trayek angkutan perdesaan yang melayani trayek di wilayah Kabupaten Sleman saat ini yang meliputi analisis : jaringan trayek, load factor, headway, jarak tempuh, waktu tempuh, jumlah penumpang dan kecepatan rerata, rute aktual, tempat menunggu angkutan dan menganalisis skema pembiayaan atau menghitung besaran subsidi yang dapat diterapkan untuk angkutan perdesaan yang terintegrasi dengan angkutan umum perkotaan yang melayani di wilayah Kabupaten Sleman.

Perhitungan biaya operasi kendaraan bus kecil dengan subsidi penuh sebesar Rp.24,406,244,917 per tahun, subsidi selisih biaya operasional sebesar Rp. 18,318,644,917 per tahun, subsidi hibah bus sebesar Rp. 18,559,117,225 per tahun dan subsidi BBM sebesar Rp.21,105,013,047. Skema pembiayaan subsidi yang direkomendasikan karena cukup logis untuk dilaksanakan adalah mekanisme subsidi selisih biaya operasional dengan sistem buy the service dengan pilihan menggunakan bus kecil.

Kata Kunci : angkutan perdesaan, analisis kinerja trayek, angkutan yang terintegrasi, skema subsidi, biaya operasional kendaraan (BOK), 


\begin{abstract}
Transport services rural areas in Sleman indicate operating performance is less well in service of nine routes. There are seven trajectories do not undergo trajectory corresponding permissions are set and one route is no longer operational.There is only one route which is still running track trajectory corresponding route permit.

The purpose of this study was to analyze the performance of services of nine transportation route rural areas serving the route in Sleman District currently includes analysis : route network, load factor, headway, mileage, travel time, number of passengers and the speed of the average, the actual, the waiting location of transport and analyzing the financing scheme or calculate the amount of subsidy that can be applied to integrated rural transport to urban public transport serving in Sleman .

Calculation of vehicle operating costs a small bus with a full subsidy for Rp. 24,406,244,917 per year, the difference in operating costs subsidy of Rp . 18,318,644,917 per year, bus subsidy grant of Rp . 18,559,117,225 per year and fuel subsidies amounted Rp. .21,105,013,047. Recommended subsidy financing scheme because it is quite logical to be implemented is a subsidy mechanism for the difference in operating costs to buy the service system with the option of using a small bus .
\end{abstract}

Keywords: Rural transport, route performance analysis , integrated transportation, subsidy schemes, vehicle operating cost (VOC) 